\title{
Evolução geológica do Grupo São Roque e importância histórica das lavras de ouro do Jaraguá-Morro Doce, SP
}

\section{Gabriel Bueno Fagundes de Freitas*, Celso Dal Ré Carneiro}

\section{Resumo}

Este projeto teve como objetivo realizar pesquisa teórico-prática acerca das relações entre geologia e controle das mineralizações das "Cavas de Ouro Históricas do Jaraguá", nos municípios de São Paulo, Cajamar, Caieiras e Santana de Parnaíba, Estado de São Paulo. A compilação de um mapa geológico atualizado da área e o estudo das relações entre associações litológicas podem auxiliar a correlação entre as características litológico-estruturais e a distribuição das ocorrências conhecidas. O produto final pode contribuir para avaliação da importância histórica das descobertas de ouro na região do Jaraguá-Morro Doce, e na recuperação de uma parte relevante da história da mineração paulista.

\section{Palavras-chave:}

Grupo São Roque, cavas de ouro, Brasil Colônia.

\section{Introdução e Objetivos}

Investigações na área de ocorrência das Cavas de Ouro Históricas do Jaraguá e Morro Doce atualizaram dados sobre vestígios de lavras de ouro, preservadas durante quatro séculos, que remontam ao Brasil Colônia (Carneiro 2002). Quatro das cinco ocorrências foram identificadas e georreferenciadas por Carneiro et al. (2010), mas a quinta está descaracterizada. As escavações são identificáveis pelo traçado linear típico e manchas de vegetação. São testemunhos da mineração colonial atualmente tombados pelo Conselho Municipal de Preservação do Patrimônio Histórico, Cultural e Ambiental da Cidade de São Paulo (CONPRESP, 2011). Desde que foram mapeadas por Carneiro (1983), intensificou-se na região do Jaraguá a expansão urbana e abertura de rodovias, que avançaram com vigor sobre os vestígios. O próprio Estado, ao autorizar a execução de obras, teve atuação decisiva na destruição de parte das feições. A pesquisa objetivou atualizar dados e elaborar mapa geológico da área de ocorrência das "Cavas de Ouro Históricas do Jaraguá", para estudos de correlação entre características litológico-estruturais e distribuição das ocorrências conhecidas. Outro objetivo do projeto foi investigar controles das mineralizações, a partir do estudo de relações entre associações litológicas, veios de material potencialmente mineralizado e referências bibliográficas modernas.

\section{Resultados e Discussão}

O estudo bibliográfico possibilitou entender a história de deformação e metamorfismo das rochas do Domínio São Roque, sobretudo as do Gr. São Roque, localizado entre a Nappe Socorro-Guaxupé e o Domínio Embu (Campos Neto, 2000). A litoestratigrafia da unidade ainda não está bem definida. Predominam metarenitos, quartzitos, filitos sericíticos, rochas metavulcânicas e rochas carbonáticas na base. A sucessão superior compreende sequência rítmica de metapelitos intercalados com metapsamitos, que podem corresponder a depósitos de corrente em ambiente marinho raso.
Dezenas de ocorrências minerais são conhecidas na área indicando mineralizações de ouro em veios de quartzo (IPT, 1981), que podem se associar a remobilização em zonas de cisalhamento. A base para confecção do mapa geológico foram dados georreferenciados de localização das ocorrências, incorporados ao mapa de Henrique-Pinto \& Janasi (2014), gentilmente fornecido pelos autores.

\section{Conclusões}

O estudo tem interesse tanto histórico quanto geológico, diante do destaque econômico da região. O produto final consiste na atualização do mapa geológico da área, buscando vincular as ocorrências à base bibliográfica previamente reunida. Foi possível fazer um estudo sobre os aspectos metalogenéticos do Grupo São Roque, mas percebe-se a necessidade de mais estudos na área para se estabelecer os padrões de mineralização.

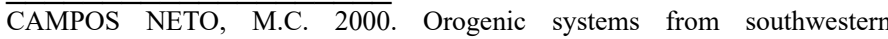
Gondwana: An approach to Brasiliano-Pan African Cycle and orogenic collage in southeastern Brazil. In U.G. Cordani, E.J. Milani, A. Thomaz Filho, \& D.A. Campos (eds). 2000. Tectonic evolution of South America. In: XXXI International Geological Congress (pp. 335-365). Brazil: Rio de Janeiro.

CARNEIRO C. D. R. 1983. Análise estrutural do Grupo São Roque na faixa entre o Pico do Jaraguá e a Serra dos Cristais, SP. São Paulo. 155p. (Tese dout. Inst. Geoc. USP).

CARNEIRO C.D.R. 2002. Cavas de Ouro Históricas do Jaraguá, SP. Os primórdios da mineração no Brasil. In: C. Schobbenhaus, D.A. Campos, E.T. de Queiroz, M. Winge, M.L.C. Berbert-Born. eds. 2002. Sitios Geológicos e Paleontológicos do Brasil. Brasília: BRASIL. Depto. Nac. Prod. Mineral (DNPM)/Serv. Geol. Brasil (CPRM). (SIGEP). p. 511-516.

CARNEIRO, C.D.R.; SANTOS, L.F.dos; SILVA, J.R.B.da. 2010. Cavas Históricas de Ouro do Jaraguá: o que resta para se preservar? Rev. Bras. Geoc., 41(1):108-120.

URL:

http://repositorio.unesp.br/bitstream/handle/11449/72332/

84856867444.pdf? sequence $=1$ \&isAllowed $=\mathrm{y}$.

CONPRESP - Conselho Municipal de Preservação do Patrimônio Histórico, Cultural e Ambiental da Cidade de São Paulo. 2011, Resolução $N^{o}$ 06/CONPRESP/2011. São Paulo, Diário Oficial da Cidade de São Paulo, 56 (51):12-14. (sábado, 19 de março de 2011).

HENRIQUE-PINTO, R.; JANASI, V.A.; CARVALHO, B.B.; CALADO, B.O.; GROHMANN, C.H. 2014. Integrated geological map of the São Roque Domain, North of São Paulo City, Brazil. Domain, North of São Paulo City Brazil, Journal of Maps, DOI:10.1080/17445647.2014.883338.

INSTITUTO DE PESQUISAS TECNOLÓGICAS DO ESTADO DE SÃO PAULO (IPT). 1981. Mapa de jazidas e ocorrências minerais do Estado de São Paulo. São Paulo: IPT. 1981. 758p. (IPT. Monografias 4, Publ. 1.171). 